\title{
Association between stress and dietary behaviors among university students: Mini-review
}

\author{
Ameera J Elshurbjy ${ }^{1}$ and Mohammed S Ellulu, ${ }^{1, *}$ \\ ${ }^{1}$ Department of Clinical Nutrition, Faculty of Pharmacy, Al-Azhar University of Gaza (AUG), Gaza, Palestine \\ ${ }^{2}$ Clinical Nutrition Specialist, Gaza, Palestine
}

\begin{abstract}
Background: Studies have shown that a significant proportion of university students globally suffer from stress. Although many studies have reported an association between psychological stress and dietary behavior, findings remain inconclusive.

Objective: The goal of this review was to determine the direction of associations between stress and dietary behaviors among university students.

Method: We searched the PubMed, ELSEVIER and other Nutrition Journal databases for studies that measured the association between stress and dietary behaviors in university students

Results: Results from this review indicate that as the stress increases the selection of unhealthy foods in female students also increases, while it has little effect on food selection unstressed male students.

Conclusion: Our understanding of the stress-eating relation is confounded by limitations inherent in the study designs; however, we can make some tentative conclusions that support the notion that stress can influence eating patterns in humans. Stress appears to alter overall food intake in two ways, resulting in under- or overeating, which may be influenced by stressor severity. Chronic life stress seems to be associated with a greater preference for energy- and nutrient-dense foods, namely those that are high in sugar and fat.
\end{abstract}

\section{Introduction}

Stress is defined as any general response of the body that either overwhelms or threatens to overwhelm the body and its ability to maintain homeostasis [1]. In general, stress occurs when there are demands on an individual that exceed his or her coping capabilities, and the reaction to stress may vary depending on the nature of the events that are occurring and the characteristics of the individual [1].

The experience of stress is likely to be a regular occurrence in the lives of new college students, given the nature of the transition that they are making [2]. Earning high grades is not the only source of stress for college students. Other potential sources of stress include excessive homework, unclear assignments, and uncomfortable classrooms. In addition to academic expectations and requirements, relations with faculty members and time pressures may also be sources of stress. Relationships with family and friends, eating and sleeping habits, and loneliness may affect some students adversely [3].

Several studies have shown there to be an association between stress and health. For example, chronic stress can lead to increased blood pressure, cardiovascular disease, diabetes, suppressed immunity and an increased incidence of depression [4,2005; Ohman, et al., 2007). Furthermore, chronic stress is also found to be associated with increased risk of obesity [2], which is an underlying factor that contributes to the chronic diseases such as cardiovascular disease and diabetes.

There is evidence to support that stress can affect an individual's health not only through direct physiological processes but also by altering behaviors which affect health $[5,6]$. Change in diet patterns is one such health behavioral response to stress observed in different population groups. Some studies have shown that stressed individuals tended to increase consumption of high calorie and high fat snack foods $[5,6]$ which may culminate in weight gain and obesity [7]. While there is widespread scientific acceptance of a relationship between psychological stress and eating behaviors the findings are inconsistent. Individuals have been found to respond to stress with either reduced (hypophagia) or increased food intake (hyperphagia) [6,8,9].

As well as the amount, the type of food eaten is also affected by stress. The intake of snack type foods, pre-prepared ready-to-eat foods and sweet foods such as chocolate, cakes and ice-cream, was found to increase among students experiencing stress $[6,8,10]$; while the intake of healthy food such as vegetables tended to decrease $[5,6]$.

\section{Review}

The impact of stress may be on the types of food selected as well as the amount of food consumed, which could possibly play a role in obesity. Recent findings suggest that high levels of stress can be associated with both increased (saturated fat consumption) and decreased (overall calories) food intake [11]. Other research has found stress to be associated with an increase in food consumed as snacks

Correspondence to: Mohammed S. Ellulu, Clinical Nutrition Specialist; Faculty of Pharmacy, Al-Azhar University of Gaza (AUG), Palestine, Tel: +970-599784862, E-mail: mohdsubhilulu@gmail.com

Key words: stress, dietary behaviors, university students

Received: June 21, 2017; Accepted: August 07, 2017; Published: August 09, 2017 
in adults [12]. Grunberg, et al. [13] found that when stressed, women were more likely to select foods high in calories and fat. Oliver et, al. (2000) found an increase in consumption of sweet high fat food and more energy dense foods. In a separate study, Steptoe, et al. [14] found that "fast food" was eaten more frequently when individuals reported greater number of events, thoughts, or situations which produce negative feeling such as annoyance, irritation, worry or frustration. Taken together, these results suggest that individuals, when stressed, may shift their preference to more palatable and energy-dense snack foods.

One important variable is how individuals use food to cope with stress and emotions. Eating has been recognized as a coping mechanism for improving and dealing with stress and emotions [15] by either under eating or overeating [16]. According to Wardle et al. (2000), there are various kinds of psychological stress that can contribute to overeating/ poor eating choices. Things such as stress at work, social stress, and perceived stress are all associated with an increased consumption of foods that are high in fat and sugar as well as being more energy-dense.

High calorie dense foods that individuals tend to consume during stressful times contribute to the increasing trend of obesity. Past research concluded that stress-induced eaters are consuming foods higher in sugar and fat content, as well as greater portion sizes, within the adult population. In a study conducted by Laitinen et al. (2002), stress-driven eaters and drinkers ate sausages, pizza, hamburgers, and chocolate more often than those who were not stress driven eaters. Repeated consumption of these foods and alcoholic beverages can account for long-term weight gain [17]. It was also found that chocolate cravings were more common among women during times of stress [18]. In the prevention of obesity, it is important to distinguish the reason behind consumption of these foods.

In a cross-sectional analysis of college students from Germany, Poland, and Bulgaria, none of the food consumption subscales of the food frequency questionnaire were associated with perceived stress or depressive symptoms in the male students. In the female students, higher consumption of carbohydrate-dense sweets and snacks was associated with higher stress, and lower consumption of fruits and vegetables was associated with both higher stress and greater depressive symptoms [19]. In the present study, we did not find any association between stress and consumption pattern of healthy food such as fruits and vegetables in either male or female students. A study by Zellner, et al. (2006) reported that women who are stressed ate more unhealthy food (snacks, chocolate/candies) than women who are not stressed, while unstressed men had significantly higher consumption of unhealthy foods than did men in the stress group. Further, a number of other studies also reported a higher consumption of "unhealthy" eating among stressed females $[6,8,20]$. One study found that although $80 \%$ of their female study participants reported that they typically ate a healthy diet, that only $34 \%$ of these females ate healthy foods when stressed [6]. Similarly, two other studies both reported that when distressed, their female study participants appeared to lose control of their eating habits which resulted in their consumption the unhealthy foods that they would usually avoid for health or weight motives [6,20]. One explanation for the gender difference in food selection patterns during stress may be the tendency of females to restrict their diet for weight control when not stressed [21,22]

The cake and chocolate biscuits preferred here by stressed emotional eaters are typically eaten as snacks. There is evidence that snack consumption may be more susceptible to stress than meals [23,24].

\section{Conclusion and Recommendations}

\section{Conclusion}

Our understanding of the stress-eating relation is confounded by limitations inherent in the study designs; however, we can make some tentative conclusions that support the notion that stress can influence eating patterns in humans. Stress appears to alter overall food intake in two ways, resulting in under- or overeating, which may be influenced by stressor severity. Chronic life stress seems to be associated with a greater preference for energy- and nutrient-dense foods, namely those that are high in sugar and fat.

\section{Recommendations}

1. Development of university programs which focus on how to provide the knowledge and resources for students to healthfully cope with stress and thus reduce the potential negative implications of stress on health.

2. Development of educational programs to promote healthy eating habits among college students.

3. Students should develop a balanced life-style and effective personal organization.

4. Students should learn specific relaxation techniques and gain perspective on problems by discussing them.

\section{References}

1. Dyson R, Renk K (2006) Freshmen adaptation to university life: depressive symptoms, stress and coping. J Clin Psychol 62: 1231-1244. [Crossref]

2. Torres SJ, Nowson CA (2007) Relationship between stress, eating behavior, and obesity. Nutrition 23: 887-894. [Crossref]

3. Ross S, Neibling B, Heckert T (1999) Sources of stress among college students College Student Journal 33: 312-317.

4. Schneiderman N, Ironson G, Siegel SD (2005) Stress and health: psychological behavioral, and biological determinants. Annu Rev Clin Psychol 1: 607-628. [Crossref]

5. Unusan N (2006) Linkage between stress and fruit and vegetable intake among university students: an empirical analysis on Turkish students. Nutrition Research 26: 385-390.

6. Zellner DA, Loaiza S, Gonzalez Z, Pita J, Morales J, et al. (2006) Food selection changes under stress. Physiol Behav 87: 789-93. [Crossref]

7. Laitinen J, Ek E, Sovio U (2002) Stress-related eating and drinking behavior and body mass index and predictors of this behavior. Prev Med 34: 29-39. [Crossref]

8. Oliver G, Wardle J (1999) Perceived effects of stress on food choice. Physiol Behav 66: 511-515. [Crossref]

9. Kandiah J, Yake, M, Jones J, Meyer M (2006) Stress influences appetite and comfort food preferences in college women. Nutrition Research 26: 118-123.

10. Serlachius A, Hamer M, Wardle J (2007) Stress and weight change in university students in the United Kingdom. Physiol Behav 92: 548-53. [Crossref]

11. Wardle J, Steptoe A, Oliver G, Lipsey Z (2000) Stress, dietary restraint and food intake. J Psychosom Res 48: 195-202. [Crossref]

12. Conner M, Fitter M, Fletcher W (1999) Stress and snacking: A dietary study of daily hassles and between-meal snacking. Psychology \& Health 14: 51-63.

13. Grunberg NE, Straub RO (1992) The role of gender and taste class in the effects of stress on eating. Health Psychol 11: 97-100. [Crossref]

14. Steptoe A, Lipsey Z, Wardle J (1998) Stress, hassles and variations in alcohol consumption, food choice and physical exercise: A daily study. British Journal of Health Psychology 3: 51-63.

15. Solomon MR (2001) Eating as both coping and stressor in overweight control. $J A d v$ Nurs 36: 563-572. [Crossref]

16. Geliebter A, Aversa A (2003) Emotional eating in overweight, normal weight, and underweight individuals. Eat Behav 3: 341-347. [Crossref] 
17. McCrory MA, Fuss PJ, McCallum JE, Yao M, Vinken AG, et al. (1999) Dietary variety within food groups: Association with energy intake and body fatness in men and women. Am J Clin Nutr 69: 440-447. [Crossref]

18. Bruinsma K, Taren DL (1999) Chocolate: food or drug? J Am Diet Assoc 99: 12491256. [Crossref]

19. Mikolajczyk RT, El Ansari W, Maxwell AE (2009) Food consumption frequency and perceived stress and depressive symptoms among students in three European countries. Nutr J 8: 31. [Crossref]

20. Liu C, Xie B, Chou CP, Koprowski C, Zhou D, et al. (2007) Perceived stress, depression and food consumption frequency in the college students of China Seven Cities. Physiol Behav 92: 748-754. [Crossref]
21. Sira N, Pawlak R (2010) Prevalence of overweight and obesity, and dieting attitudes among Caucasian and African American college students in Eastern North carolina: A cross-sectional survey. Nutr Res Pract 4: 36-42. [Crossref]

22. Yahia N, Achkar A, Abdallah A, Rizk S (2008) Eating habits and obesity among Lebanese university students. Nutr J 7: 32. [Crossref]

23. Lowe MR, Fisher EB Jr (1983) Emotional reactivity, emotional eating, and obesity: a naturalistic study. J Behav Med 6: 135-149. [Crossref]

24. Oliver G, Wardle J, Gibson EL (2000) Stress and food choice: a laboratory study. Psychosom Med 62: 853-865. [Crossref]

Copyright: (02017 Elshurbjy AJ. This is an open-access article distributed under the terms of the Creative Commons Attribution License, which permits unrestricted use, distribution, and reproduction in any medium, provided the original author and source are credited. 